\title{
As cinzas da Coleção Perseverança, o Quebra de Xangô ainda arde
}

\author{
Anderson Diego da S. Almeidal
}

DOI 10.20396/eha.vil4.3321

\section{Cortejo da Maldade}

Na noite de $1^{\circ}$ de fevereiro de 1912, um grupo de ex-milicianos, denominado Liga dos Republicanos Combatentes, sai em passeata na cidade de Maceió, capital do estado de Alagoas, invadindo todos os terreiros de matriz africana.

A conhecida Operação Xangô, nome dado pela Liga, teria se formado a partir da argumentação de que o então governador, Euclides Malta, era assíduo frequentador nas Casas de Xangôs, nome popularmente dado aos terreiros de Alagoas e Pernambuco ${ }^{2}$ e que administrava o Estado sob a proteção dos deuses africanos, que o mantinham no poder há mais de uma década. Inconformados com a possibilidade de uma nova reeleição de Malta, o grupo miliciano constrói um clima de terror em toda a capital, atacando funcionários e familiares do governo. Numa destas tentativas, o governador sai fugido, em um trem, para à cidade de Recife, deixando seu cargo para ser ocupado pelo presidente da câmara.

Livre do infortúnio que acreditava ser Malta, a Liga segue seu plano e resolve atacar pais e mães de santo. Rafael afirma que na noite do quebra-quebra, muitos dos terreiros se preparavam para iniciar suas festividades, em homenagem à Oxum, que se prolongava há dez dias. E quando os atabaques anunciavam o toque, muitos religiosos receberem a turba de revoltados que, sem piedade, bateram, sangraram e destruíram pejis. A crueldade era tamanha que Tia Marcelina, negra da costa, fundadora do Xangô em Alagoas, acusada de ser mãe de santo de Malta, foi brutalmente espancada com um golpe de sabre e, com lágrimas em meio ao sangue que escorria da cabeça, clamava a seu orixá Xangô, "ê ô, Cabecinha!", vendo muitos dos seus pertences serem queimados na frente de sua casa:

Diversos objetos sagrados, utensílios e adornos, vestes litúrgicas, instrumentos utilizados nos cultos, foram retirados dos locais em que se encontravam e lançados no meio da rua, onde se preparava uma grande fogueira. Naquela via pública, entre rosários e colares de

\footnotetext{
1 Doutorando em Artes Visuais: História, Teoria e Crítica de Arte - Universidade Federal do Rio Grande do Sul - UFRGS. E-mail: andersondiego. almeida@gmail.com

2 DUARTE, 1974.
} 
ofás, foi colocada, ainda, a imagem de um santo em forma de menino, que muitos afirmaram se tratar de "Ali Babá", a qual ficou exposta à zombaria dos que passavam³.

Depois da queimada e das inúmeras invasões, parte dos objetos foi levada pelos revoltados para à sede da Liga. Assim, enquanto as fogueiras ainda ardiam em algumas ruas da capital e o Sol do dia 2 dava seus primeiros sinais, os objetos que não foram queimados continuavam expostos, simbolizando a "bravura" e a retomada da ordem no Estado.

Depois de um dia naquele lugar, os objetos foram doados à antiga Sociedade Perseverança e Auxílio dos Caixeiros de Maceió, espécie de associação de funcionários do comércio da capital, que possuía uma sala expositiva. As peças, lá ficaram, por quase quarenta anos.

\section{A Coleção Perseverança e as marcas do Quebra-Quebra}

Após Abelardo Duarte ficar ciente de que os objetos estavam em um porão da extinta Sociedade Perseverança e que os mesmos poderiam ser vendidos para um museu americano, as peças são levadas para o Instituto Histórico e Ceográfico de Alagoas, em 1950, e passa a integrar o acervo com o nome Coleção Perseverança, homenageando, assim, a instituição que a abrigou por 38 anos. "Sem valor para os que retinham, essa coleção é, para o Instituto Histórico e Geográfico de Alagoas, de subida importância cultural. [...] Guardamo-las por isso"4.

No discurso de abertura, Brandão ${ }^{5}$ explicita:

O Museu Afro-Negro da Perseverança, atualmente incorporado ao Museu do Instituto Histórico de Alagoas sob o título de "Coleção Perseverança" é talvez uma das ricas e preciosas coleções existentes no Brasil, em matéria ligada aos cultos negros. Compõem-se, segundo identificação por nós e Abelardo Duarte e revista pelo conferencista desta noite, 10 estatuetas esculpidas em madeiras (oxês) representativas de orixás africanos entre os quais, Oxalá, Ogum China, Ogum Taió, Xangô Nilé, Ogum Londé, lemanjá, Oxum-Ekum, Xangô Bomim; de mais de 50 pulseiras de latão da deusa das águas Oxum, de fetiches de Ibeji ou dos gêmeos (Cosme e Damião, de Xararás de Omolu, deus da varíola (S. Lázaro); de Nanan Burucu; Eirus ou Pachorós de rabo de boi de Oxossi, Abebês (leques) de Oxum e de lemanjá (a sereia do mar); ferramentas de Ogum; capangas de Oxossi?; adamantás e Belebês (palmatórias) de Ogum ou de Oxossi; assentos de Ogum e de Exú, filas de Xangô Nilés; gorros de Xangô Bomim, de Ogum Taió, de lansan, Azuleiju; espada de lansan e de Ogum.

3 RAFAEL, 2012, p. 32

Op. cit., 1974, p. 11.

5 BRANDÃO, 1950 , p. 5-6. 
Peitoral e capacete de Ogum China (só o capacete avaliado em 1912 em 500,00); capacete de Oxum; e colete de Ogum Diaci; agogôs de ferro, adjás, xexerés, e várias outras peças, muitas de interessante feitura e às vezes de real valor artístico, afora naturalmente a valia e a importância etnográficas e históricas que possuem.

Na mesma noite de inauguração, o médico René Ribeiro profere sua palestra intitulada Significado dos Estudos Afro-Brasileiros. Em seu discurso é possível identificar sua preocupação com os estudos culturais e com o africano. A importância que se deve dar para que se compreenda o lugar do fazer das culturas negras na formação cultural do Brasil. Assim, ao analisar a Coleção Perseverança, discorre que

São assim elementos formais e estructurais de uma tradição religiosa que se revelam: deuses de um panteon; sugestões sobre iniciação e dedicação de cada fiel a certas divindades pela existência de coroas e colares distintivos; sobre o cerimonialismo dos "toques" e das oferendas; sobre a utilização de práticas divinatórias [...]. Intrinsecamente tais objectos sugerem o estudo do estilo dessas composições escultóricas - em várias das figuras humanas notemos desde logo a inequívoca presença do santeiro e da tal ha europeia nas vestes e nas feições desses orishas meio travestidos em santos romanos. Os materiais dos outros objectos e seu tratamento, o uso de determinadas combinações de cores, indicam técnicas ou valores tradicionais respeitados naqueles grupos de culto, de onde provieram tais objectos $[\ldots]^{6}$.

De acordo com Lody':

O grande mérito da Coleção Perseverança está justamente no que se conseguiu reunir de documentos do homem alagoano, portador dessa grande herança afro-negra e afroislâmica. Ele atesta como conhecedor dos deuses africanos, das elaboradas técnicas artesanais de fazer objetos trabalhados em búzios, metais, couro e madeira; onde está transparente esse ethos africano. Essa é uma arte em que a comunidade assume a autoria, onde a moral e a ética da sociedade estão comprometidas com a memória, sendo decisivamente o viço da identidade o grande alimento dos processos.

Há, nos mais de 200 objetos, uma plasticidade que carrega as marcas do africano e seus descendentes que foram violentados e perseguidos pela polícia e por uma sociedade, dita católica, que não fazia questão de esconder seu racismo e desprezo com as religiões de matriz africana. É possível encontrar objetos parcialmente queimados, com cinzas, sangue, rasgos e com sinais de destruição daquela noite que ficou marcada na memória de filhos, pais e mães de santo. Mas, por que não

\footnotetext{
6 RIBEIRO, 1952, p. 10.

7 LODY, 1985, p. 10.
} 
foram destruídos em sua totalidade? Por que preservados?

É importante enfatizarmos que estas peças foram salvas durante as invasões com o intuito de manterem viva a memória do grupo miliciano que desejava ter seus aliados, Clodoaldo da Fonseca e Fernandes Lima, no cargo de Governador de Alagoas. Assim, os objetos que não foram destruídos, segundo Jornal de Alagoas de 1912, mantinham ligação e, de certa forma, pertenciam a Euclides Malta. Eram prova de que este frequentava os terreiros.

Num dos artigos da série Bruxaria, esta divulgada entre os dias 4 e 8 de fevereiro de 1912 pelo Jornal de Alagoas, as peças apreendidas pertenciam, em sua maioria, ao terreiro de Tia Marcelina. Nesta perspectiva, selecionamos algumas peças, dentre as mais de 200 que compõem o conjunto, para elucidar a memória do Quebra de Xangô e a relação das peças com Euclides Malta. (Figura 1)

A primeira delas seria um dos protetores de Malta que, através da força dos orixás, era mantido no cargo há três mandatos. A peça foi construída em madeira e seguidamente envernizada. Observa-se a forte influência do entalhador com os traços da escultura africana, seja na simetria, postura e técnica de feitura. A cor vermelha, sincretizada a São Jorge e as correntes que simbolizam o ferro são as principais características da peça. (Figura 2)

A citação abaixo descreve um dos momentos da invasão à casa de Marcelina e o que foi encontrado num quarto que pertencia ao seu suposto filho de santo. Nela, identificarmos a referida escultura que se encontra na Coleção Perseverança:

A guisa de petição, jogado aos pés de um "oghum", foram encontrados muitos pedaços de papel escritos a tinta ou a lapis e cuja reprodução a nossa Penna de jornalista repelle. Entre esse papeis um nos despertou attenção, porque logo no alto tinha gravado o nome do sr. Governador e assim dizia: Dr. Euclides Malta [....] Roga a "baba", "oghum" e a "cangou" pelo seu parente ${ }^{8}$.

Vejamos outra citação que, na mesma perspectiva da anterior, referencia a imagem do governo às esculturas apreendidas no quebra-quebra:

Disseram que o "xangô bomim", um "santo" de madeira com cara preta, era o protector do dr. Euclides Malta na sua qualidade de chefe político; que "oghum taió" o defendia contra os inimigos, rogando aos deuzes todas as garantias para o governador; e que "xangô nilê", um "santo" aleijado, de muleta e filho ao braço, era o que mai rapidamente se apossava do dr. Euclides, entrando lhe na cabeça'.

\footnotetext{
8 Foi mantida a escrita original do documento. JORNAL DE ALACOAS, 4 FEV. 1912, p. 2.

9 Foi mantida a escrita original do documento. Ibid., p. 2.
} 
[Figura 1]

Manchete do Jornal de

Alagoas.

Fonte: Arquivo do Instituto Histórico e Geográfico de Alagoas.
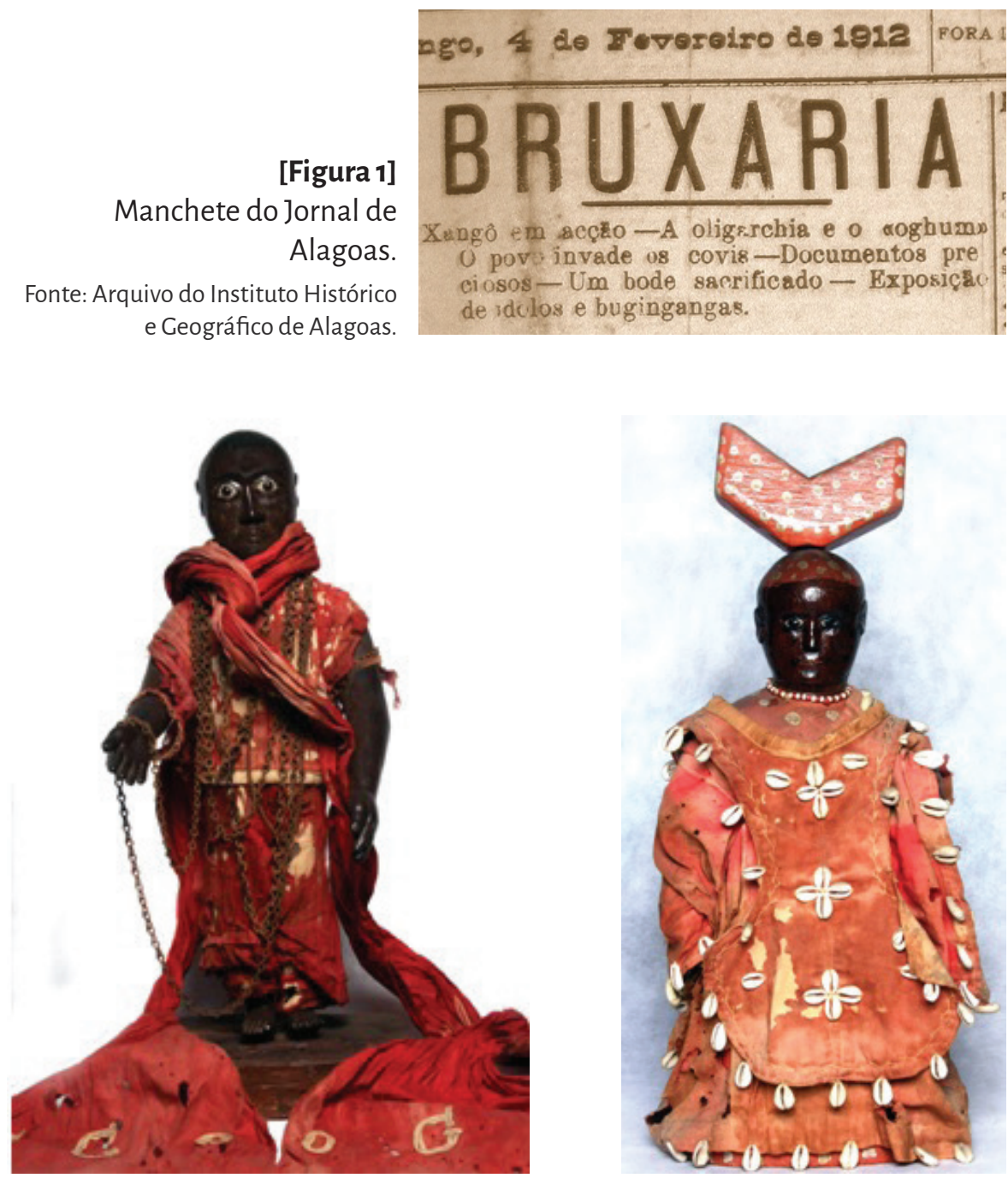

Geográfico de Alagoas.

[Figuras 4 e 5]

Capacete. $26 \mathrm{~cm}$ (altura) $\times 18 \mathrm{~cm}$ (circunferência-base); detalhe costurado na base superior. Fonte: Arquivo do Instituto Histórico e Geográfico de Alagoas.

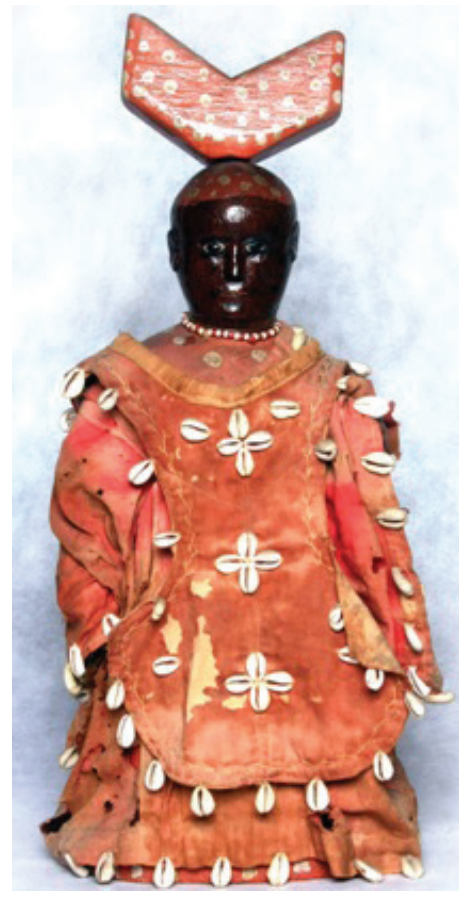

[Figura 3] Escultura ritual Xangô. $38 \mathrm{~cm}$ (altura) $\times 8 \mathrm{~cm}$ (profundidade).

Fonte: Arquivo do Instituto Histórico e Geográfico de Alagoas.

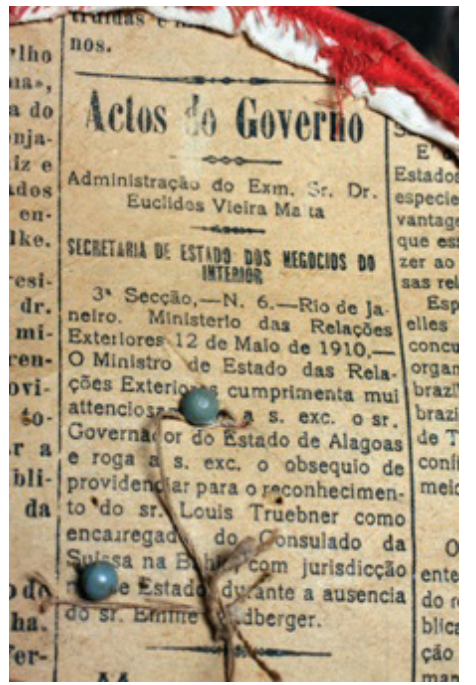


O trecho nos informa mais uma escultura que estaria ligada a Malta. Trata-se de uma imagem esculpida em madeira, cujo elemento no topo, um machado de duas faces, também conhecido como oxê, é alusivo ao orixá Xangô. Observar que a peça carrega uma espécie de indumentária utilizada no ritual da Igreja Católica. Malta era um oligarca católico. Provavelmente, a dualidade da imagem entre o candomblé e o catolicismo, elemento sincrético muito comum nos terreiros nordestinos, é uma característica alusiva ao governo. (Figura 3)

Essas duas esculturas, mesmo que descritas de forma breve, nos apontam a relação que tem a Coleção Perseverança com a memória do Quebra do Xangô, através dos sinais visuais de feitura, que estão associados à imagem de Euclides Malta. Poderíamos, neste aspecto, continuar descrevendo outros indícios que nos permitem atestar o quão esses objetos se aproximam de uma feitura local, da possível mão- afro-alagoana e das marcas de sobrevivência que o africano deixou nas peças. Mas, preferimos enfatizar, com estes dois exemplos, o que poderemos encontrar nas outras peças que estão além da feitura, tratam-se de documentos sobre a memória do Quebra de 1912 e sobre a identidade do homem afro-alagoano. São adornos, indumentárias, objetos do cotidiano, instrumentos musicais que precisam ser lidos atentando-se sobre seus significados outros, além do religioso.

Um destes significados além do religioso está presente na peça a seguir. Trata-se de um capacete montado em papelão, arame e tecido, que traz franjas na parte superior e ao redor da estrutura de base e lantejoulas douradas. Pelas cores, vermelho e preto e pela estrutura que se forma em seu topo, alusivo a um assentamento, acreditamos ser referência a Exu. Um adendo bastante significativo diz respeito a Euclides Malta ter sido apelidado de Leba, nome popularmente associado a Exu, pelos católicos, como espírito do mal.

O mais instigante que atrai nosso olhar, em afirmar essa ressignificação, é visto no detalhe que está costurado na parte da base superior do capacete. Trata-se de uma notícia de um jornal alusiva ao governo Malta. Notar que o papel está costurado por dentro. Não sabemos se a peça foi trazida da África ou se foi produzida em Alagoas, mas, sem dúvidas podemos atestar que o negro em terras alagoanas ressignificou a estética africana, adaptando o objeto para a realidade local. Outro adendo muito importante é pensarmos que tal objeto serviu como prova para afirmar que Malta era frequentador dos terreiros, chegando a receber o título de "Papa do Xangô Alagoano"10. (Figuras 4 e 5)

10 RAFAEL, 2012. 
Os três exemplos anteriores é um breve recorte semântico do que esconde as várias camadas que constituem a Coleção Perseverança. São memórias que continuam a reverberar e que necessitam vir à luz para que compreendamos o Quebra do Xangô como um episódio arquitetado sobre o ideal do silenciamento do povo africano. As peças que apresentamos, como já afirmamos, vão muito além de objetos rituais, tratam-se de imagens que denunciam outras histórias.

\section{As chamas do Quebra ainda ardem}

O que podemos dizer com esta breve narrativa é que parte de nossa investigação aponta para uma história que não cessa de se reconfigurar e, aparentemente as cinzas que estamos soprando, os indícios apontados, nos levam a afirmar que a coleção carrega além das marcas de feitura local, sinais de maldade, racismo, negligência, mentira e manipulação da imprensa, que foi conivente com o atentado, e de uma sociedade preconceituosa que tentava manter imagem de religiosa e "evoluída intelectualmente". Se as peças são foram vistas como provas da relação de Euclides malta com os terreiros, não podemos afirmar, pois nossa análise baseou-se nos indícios de um jornal que apoiou o quebra-quebra e que, porventura, pode ter manipulado as fontes.

Nosso objetivo foi apresentar um breve recorte mostrando como a história do Quebra de Xangô se entrelaça com a história de Euclides Malta, com a perseguição aos negros e aos terreiros e reverbera nas peças apreendidas. Lá estão, silenciadas, outras histórias que precisam sair da escuridão.

Se há muito a identificar, há muita história a escrever. São teias e mais teias que precisam ser desfeitas e novamente tecidas sobre outros aspectos, aqueles que consideramos mais importantes e que se distanciam de uma visão branqueada e racista, o negro como o centro, como o elemento principal que sofreu e foi silenciado.

Certamente, há muito a pesquisar e dizer sobre o Quebra de Xangô a partir da leitura da Coleção Perseverança. As possibilidades são tamanhas. Os vestígios e resquícios daquela noite violenta ainda "gritam" e "ardem". 


\section{Referências Bibliográficas}

BRANDÃO, Théo. Saudação e agradecimento. Discurso pronunciado no Instituto Histórico de Alagoas em 16 de setembro de 1950.

DUARTE, Abelardo. Catálogo ilustrado da Coleção Perseverança. Maceió: Departamento de Assuntos Culturais da Secretaria de Educação e Cultura de Alagoas, 1974.

JORNAL DE ALACOAS. Bruxaria: Xangô em acção - a oligarchia e o 'oghum'. O povo invade os covis - Documentos preciosos - um bode sacrificado - Exposição de ídolos e bugigangas. n. 24, ano V. Maceió, 04 Fev. 1912, p. 1.

JORNAL DE ALACOAS. Bruxaria: a música e cantigas dos filhos de santo - A camara dos mysterios - Xangô em confusão - Notas e informações. n. 26, ano V. Maceió, 07 Fev. 1912, p. 1.

LODY, Raul. Coleção Perseverança: um documento do Xangô alagoano. Maceió: Universidade Federal de Alagoas: Rio de Janeiro: FUNARTE/Instituto Nacional do Folclore, 1985.

RAFAEL, Ulisses Neves. Xangô rezado baixo: religião e política na Primeira República. São Cristóvão: Editora UFS; Maceió: Edufal, 2012.

RIBEIRO, René. Significado dos estudos afro-brasileiros. In: Revista do Instituto Histórico de Alagoas. 1952. V. XXVI, p. 7-16. 